\title{
Case study of urban property development along the Barcelona seafront employing sustainable strategies
}

\author{
Ezequiel Uson Guardiola, PhD \\ Department of Architectural Projects \\ Polytechnic University of Catalonia (UPC). \\ Barcelona, Spain
}

\author{
Josep Vives Rego, PhD \\ Department of Microbiology \\ University of Barcelone (UB) \\ Barcelona, Spain
}

\author{
Diana Uson Maimo, PhD student \\ Architecture \& Sustainability Research \\ Unit in Barcelona \\ Barcelona, Spain
}

\begin{abstract}
This article describes the development plan which has been drawn up to reurbanise the seafront "Área de las térmicas dels Besos". This combines residential and tertiary uses, infrastructure and also free areas for museum uses in the great industrial building of the old power station. The current plan will make it possible to gain a kilometre of beach for the use and enjoyment of the citizens of Barcelona. It will also provide the municipality of Sant Adriá de Besos with access to the sea. The most original contribution of this plan lies in its aim to collaborate to sustainable urban development. It plans to do this by incorporating strategies that will make it possible to generate urban growth with a minimum environmental impact and with low carbon emissions.
\end{abstract}

Keywords; Barcelona seafront; sustainable urban development; the Besos power station area

\section{INTRODUCTION:}

The only zone of the Barcelona seafront that has not yet been urbanised is located on the left bank of the mouth of the River Besos. This seafront area of 28 ha, which includes almost one $\mathrm{km}$ of beach, is known locally as the "Área de las térmicas dels Besos" (the Besos power station area).

The current image of this polygon of the Master Plan for the Metropolitan Area of Barcelona is dominated by a distinctive building with three $220 \mathrm{~m}$ chimneys. This was once a power station, but now forms part of the historical memory of Barcelona. "Fig. 1"
Until its closure in 2011, this building supplied an important percentage of the electricity consumed in Barcelona. It is now the last visible sign of what was once the great industrial area of the "Poble Nou" area of the city and of what (towards the end of the 19th century) had been referred to as the Manchester of Catalonia.

The celebration of the 1992 Olympic Games and the 2004 Universal Forum of Cultures signified the dismantling of the old, and then obsolete, industrial metal-working and chemical plants and their transfer to other industrial areas. This also opened the door for property development along the Barcelona seafront.

This urban renewal of the city's seafront would probably have also reached the power station area if the process had not been interrupted by the bursting of Spain's property bubble in 2008. This also heralded the onset of the present crisis in country's construction sector

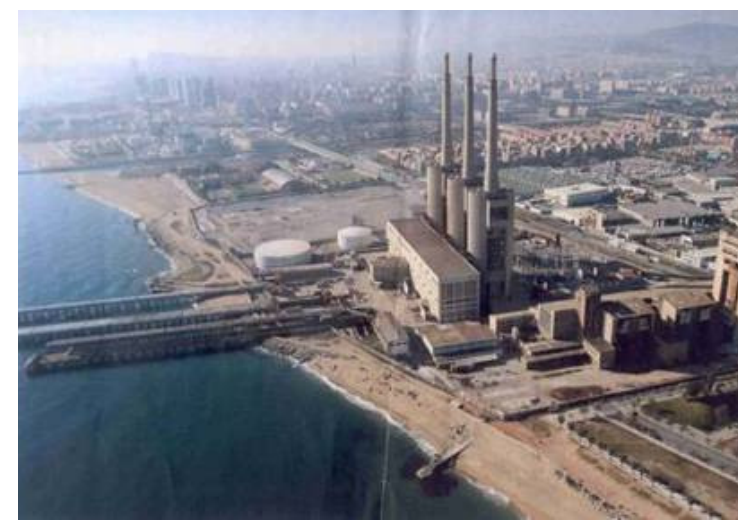

Figure 1. Present-day view of the former power station building and the area subject to the Plan 


\section{THE URBAN DEVELOPMENT OF SANT ADRIÁ DEL BESOS}

A. Origins and previous urban development policy.

Sant Adriá del Besos is a municipality with a current population of 35,000 which lies within the metropolitan area of Barcelona. To be a little more precise, it is located in the delta of the River Besos, between the municipalities of Barcelona, Sta. Coloma de Gramanet and Badalona. "Fig. 2" This urban nucleus originated in the second half of the 19th century. It was the product of the industrialisation of an area across which a railway line - the first on the Iberian Peninsula was constructed between Mataró and Barcelona in 1860. [1]

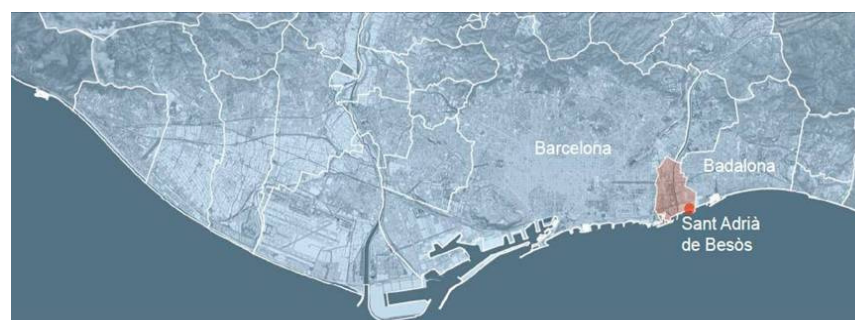

Figure 2. The Besos area

Throughout the later 19th century and during the first half of the 20th century, large-scale industry was attracted to the areas along this railway line. This blocked access to the sea from the city of Barcelona in this area. This lack of access continued until extensive urban remodelling was carried out in preparation for the 1992 Olympic Games.

As a result of the large-scale industrial development of the metropolitan area of Barcelona in the 1970s, the Besos delta was colonised by a wide range of different types of informal housing which provided accommodation for successive waves of migrants.

The first urban nucleus, which consisted of rather precarious, self-built housing, was formed by what were popularly known as the "barrio de la Bota" (Bota neighbourhood) and "el barrio de La Catalana" (the Catalan neighbourhood). These settlements mainly housed migrants who had arrived in Barcelona from the rest of Spain, looking for work in the city's large industrial areas. This was also when the great Besos power station was constructed next to the sea in order to provide electrical energy for all of the industry in the surrounding area.

This predominantly precarious housing situation and the informal nature of this settlement continued until the 1970s, when the La Mina neighbourhood (with 2,800 housing units) was constructed in order to rehouse the inhabitants of this marginal housing. [2]

\section{B. Major events}

The great urban transformation of the whole seafront of Barcelona occurred as a consequence of the city hosting the 1992 Olympic Games. As a consequence of this major international event, heavy industry was moved away from this area and the city regained access to the sea. As a result, the coastal strip acquired the new, urban residential and service functions that now form part of the great beach of Barcelona. "Fig. 3"

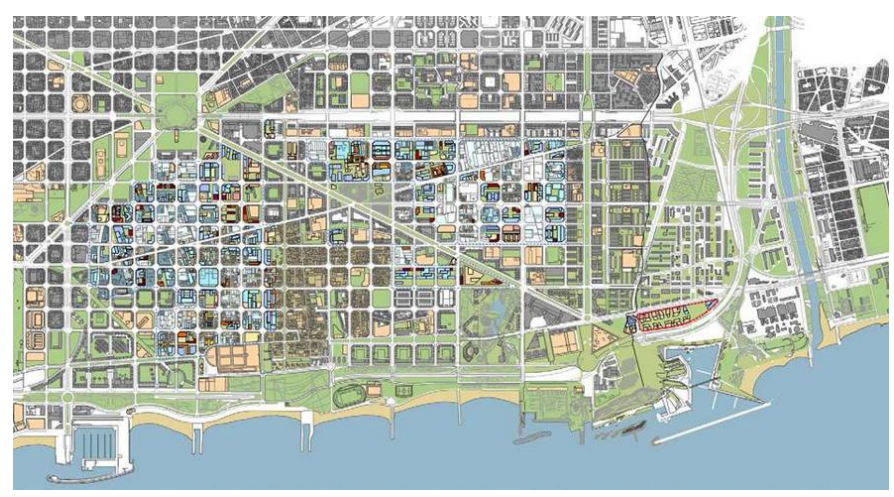

Figure 3. Current city map of Barcelona whit Besos area on right side

The 1980s saw the creation of the Besos Consortium, whose main function was to channel and generally clean up the River Besos and its immediate surroundings. This also included supplying some major environmental infrastructure, including an open-air treatment plant for waste waters from the Besos basin, in the area nearest the mouth of the river.

Coinciding with the celebration of the Universal Forum of Cultures, in 2004, "Fig.4" this waste water treatment plant was covered, a solid waste incinerator was constructed and a gaspowered and a local district heating (districlima) were built. This made it possible to take advantage of residual energy in order to provide hot and cold water for the whole neighbourhood of Poble Nou.

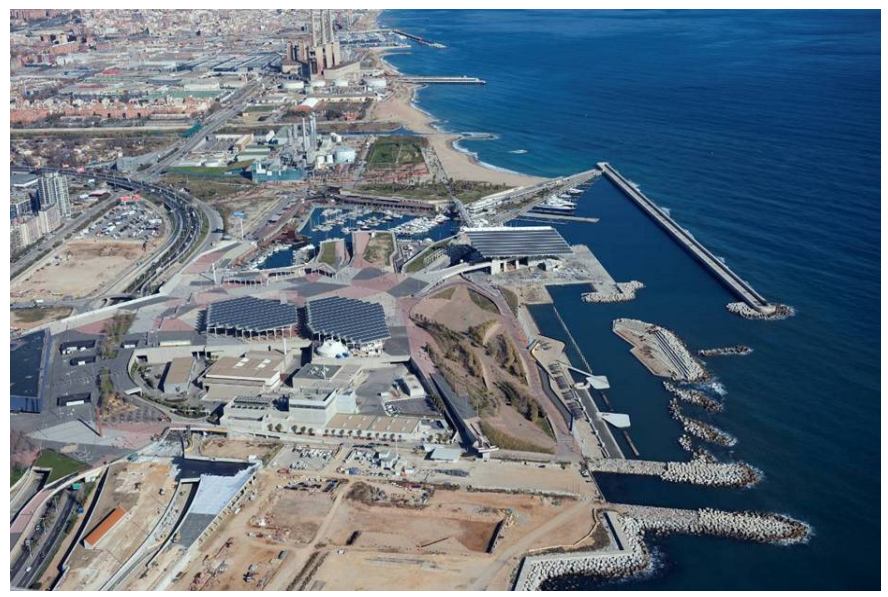

Figure 4. Present-day view of the Forum of Cultures area

The use of new technologies to generate electricity based on less polluting sources rendered the old Besos power station obsolete, with it definitively closing in 2011.

At present, the building remains as the last visible sign of what was once the great industrial neighbourhood of Poble 
Nou, "Fig. 5" and what had once been known as the "Manchester of Catalonia". [3]

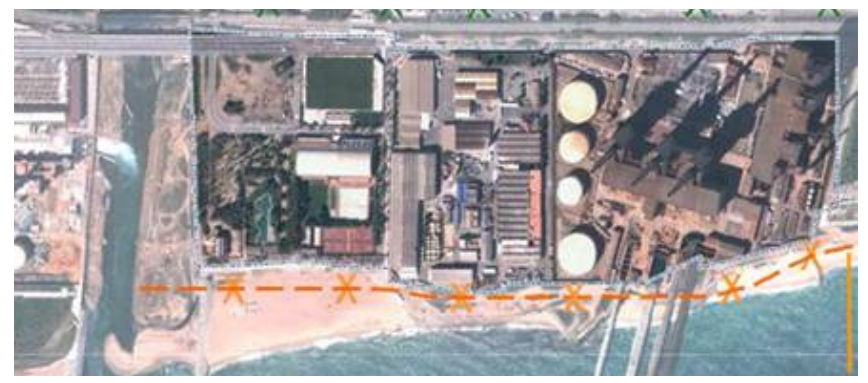

Figure 5. The area subject to the Plan

\section{BASIS FOR THE URBAN PLANNING OF THE POWER STATION AREA}

\section{A. The metropolitan environment}

The part of the Besos area known as "Barcelonés Nord" currently includes a continuous urban area with a population of 365,000 . The vast majority of its inhabitants occupy high density housing distributed amongst with industrial estates that are subject to a process of urban transformation. [4]

Within this urban context, the Besos power station area is one of the elements earmarked for urban remodelling under the 1973 Master Plan for the Metropolitan Area "Fig. 6".

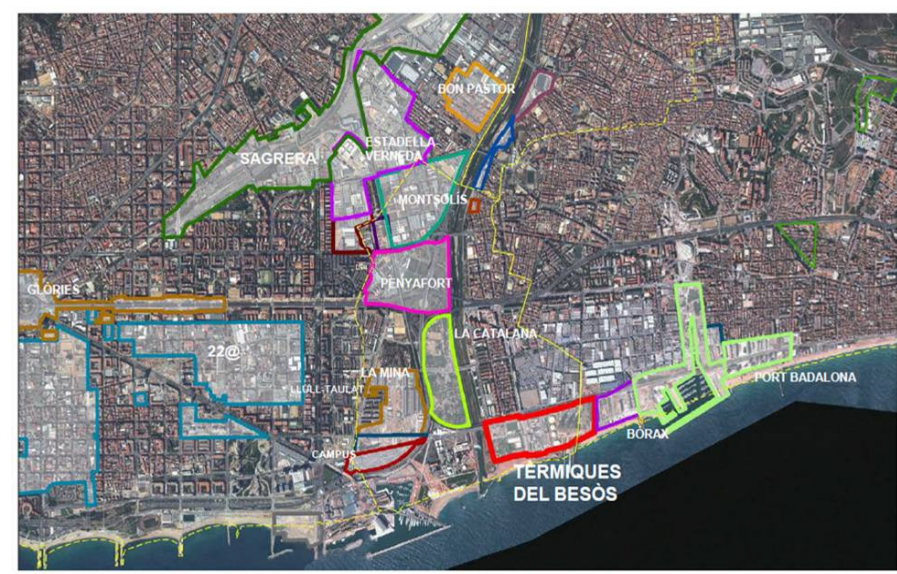

Figure 6. Areas of urban transformation and consolidation along the Barcelona seafront and in the Besos area: new areas of centrality and major amenities

\section{B. Biodiversity}

As a consequence of its strategic position at the mouth of the River Besos, the study area is of great environmental value and needs to be both conserved and further exploited.

The river basin itself forms an ecological corridor between the sea and the coastal uplands and boasts a rich biodiversity.
Various public administrations have carried out projects to improve and restore the local environment and this has resulted in water of good quality and has helped to turn the banks of the river into a linear park "Fig.7".

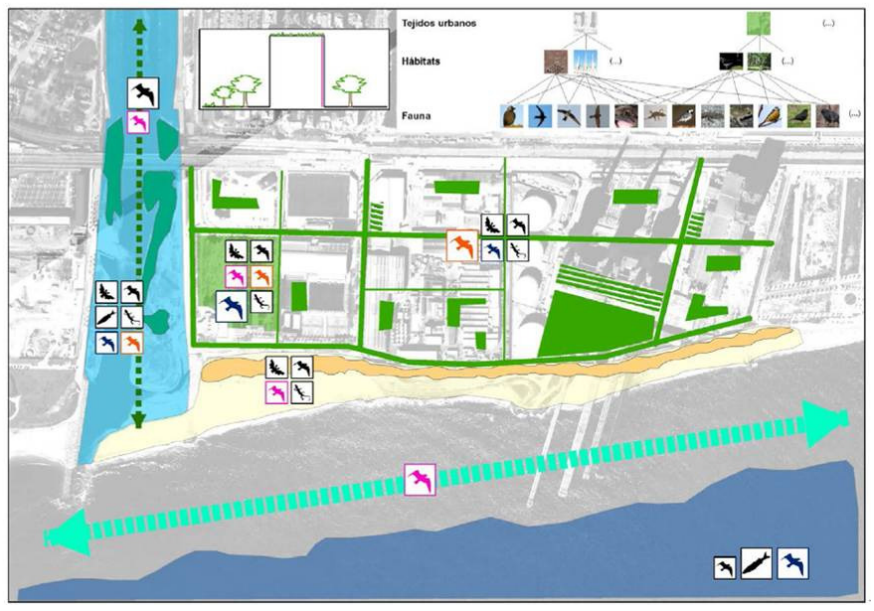

Figure 7. Biodiversity

\section{Water Resources}

The River Besos is the second most important river in Barcelona's metropolitan area. It has a water basin of some $1,000 \mathrm{~km} 2$ with a very irregular regime, which is typical of a Mediterranean climate.

In the past, the Besos delta aquifer served as a source of water for the city of Barcelona. However, in the 1970s and 1980 s, it suffered a process of salinisation. This was the result of its overexploitation and the invasion of sea water, though it is now protected from such problems.

Part of the aquifer corresponds to the subsoil under the power station, which includes a large reserve of fresh water that prevents the invasion of sea water. Although this provides protection, the use of these waters that lie under the riverbed could also prove problematical as they have been polluted as a result of their recent industrial use "Fig. 8".
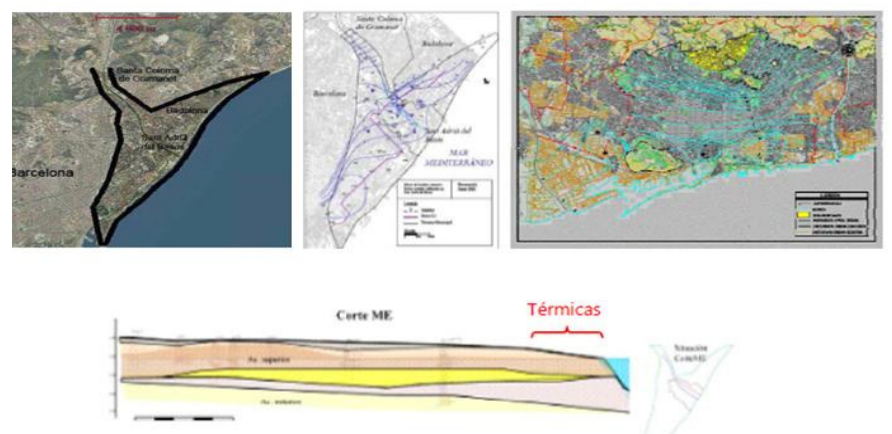

Figure 8. Water resources, (groundwater) 


\section{Energy resources}

\section{1) Energy from waste}

The major industrial installations located on the right-hand bank of the River Besos and, more specifically, in the Forum area, are based on cogeneration.

They include a solid waste incineration plant, a waste water treatment plant and a gas power plant. All of these installations generate energy from waste in the form of electricity and heat. The Metrofang power plant makes it possible to recover $100 \%$ of the heat energy obtained from burning waste and the PVE incineration plant makes it possible to recover $30 \%$ of the energy in the form of electricity. This energy then feeds the district power station (districlima) and provides hot and cold water to the Poble Nou neighbourhood. Given its proximity, it could also supply energy to the area of new urban development around the power stations.

\section{2) Renewable forms of energy}

The potential for generating energy based on renewable sources is very high:

- Photovoltaic solar energy

- Solar thermal energy

- $\quad$ Eolic (mini, onshore, offshore)

The proposed installations combine these different strategies to achieve the maximum energy rating of the CTE in the new buildings. This is achieved by using waste energy from the major treatment plants in the area and also by taking advantage of renewable forms of energy that could be used to cover $100 \%$ of the demand for energy "Fig. 9".

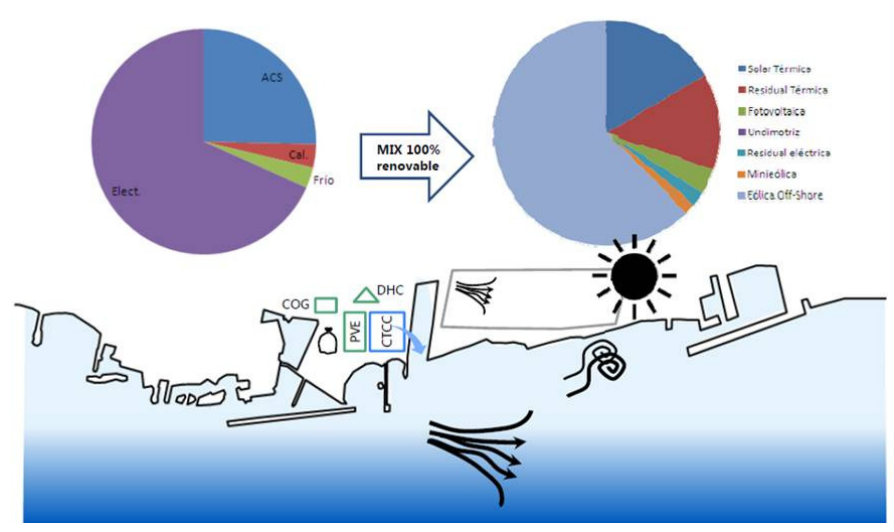

Figure 9. Energy mix

\section{E. Threats: coastal areas facing climatic change}

The UN report published on 2nd November 2014, which contained a 5,000 page summary of research carried out by 800 scientists, confirmed the existence of climatic change and that this is a phenomenon induced by human activity.1

Since the 1950s, when the scientific community began to spread the first warnings about climatic change, global warming has become increasingly evident. The concentration of $\mathrm{CO} 2$ in the atmosphere has now reached 400 ppm and it has been shown that the average global temperatures rose by $0.85{ }^{\circ} \mathrm{C}$ between 1880 and 2012. As a result, the planet's permanent arctic ice cap shrank has been shrinking at a rate of between $3.5 \%$ and $4 \%$ per decade since 1973.

This has been accompanied by a progressive acidification of the world's oceans (which has increased by $26 \%$ since the preindustrial era) and a rise in sea-level $(20 \mathrm{~cm}$, since 1901).

This synthesis report summarised what science knows about the global warming that has taken place to date.

It concluded that if emissions of the three main gases released as a result of the combustion of fossil fuels (carbon dioxide $(\mathrm{CO} 2)$, methane $(\mathrm{CH} 4)$ and nitrous oxide (NO2)) are not curtailed, the result will be ever more frequent incidences of extreme meteorological phenomena. An average increase in temperatures of $4.8{ }^{\circ} \mathrm{C}$ is forecast for between now and 2100; this would be associated with an average increase in global sea levels of around $0.82 \mathrm{~m}$ with respect to current levels.

This will, without a doubt, have a great impact on coastal areas, with land currently inhabited by millions of people being submerged.

In the words of the co-president of IPCC Work Group III, Youba Sokona, “....What we need are appropriate policies and institutions .... The longer we wait before taking action, the greater will be the cost in terms of adapting to and mitigating climatic change...".2

It is for this reason that the challenges are importants: Port cities and those with waterfronts face numerous (urbanistic, economic, environmental, etc.) challenges and their reconversion therefore also constitutes an interesting opportunity for their reorganisation and dynamisation.

From the discipline of urban planning, it is necessary to confront the risks to the natural environment associated with climatic change. With this in mind, urban planning should seek to incorporate strategies for sustainability that will help to combat climatic change through a transition towards a low carbon emission economy. [5]

This is both technically and economically viable and will be absolutely necessary if we wish to prevent the flooding of coastal areas as a result of rising sea levels.

\footnotetext{
${ }^{1}$ Synthesis Report ARS, intergovernmental panel against climate change (IPCC), Fifth Assessment Synthesis Report, $2^{\text {nd }}$ November 2014

${ }^{2}$ The fifth UN report on climate change, El PAIS, $3^{\text {rd }}$ November 2014
} 


\section{PLANNING GUIDELINES FOR THE NEW MASTER PLAN OF THIS AREA}

In the 1976 Master Plan for the Metropolitan Area of Barcelona, the area on the right bank of the River Besos was qualified as one of transformation.

With the transfer of industrial activities and the definitive closure of the old power plant, a very large space has been left free of buildings. This land, which lies along the seafront, covers an area of 28.52 hectares. This is a unique asset that has no equal in the rest of the metropolitan area and is a location that offers centrality and new opportunities. It is well connected to existing transport infrastructure and therefore easily accessible and well-connected to the major urban axes "Fig. 10".

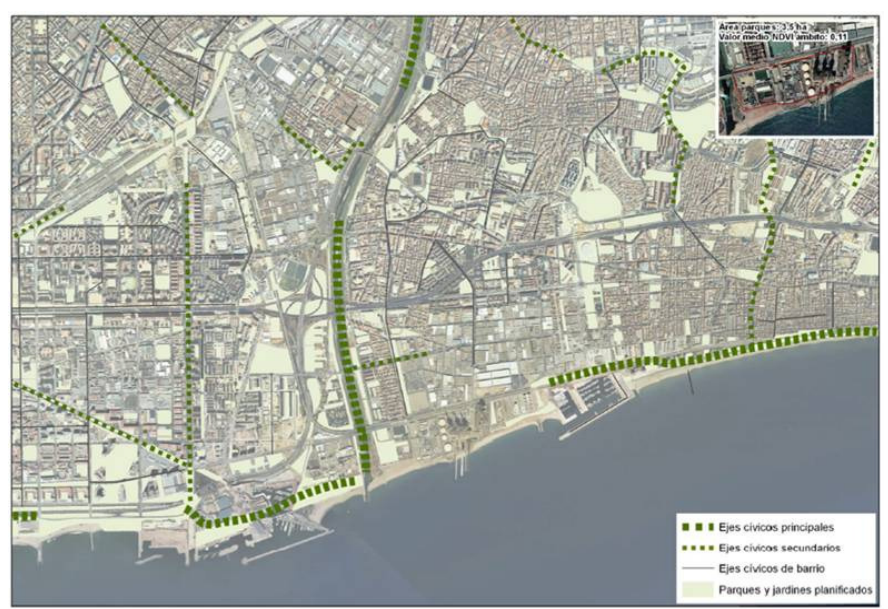

Figure 10. Position of centrality and relations with the main civil axes

\section{A. General guidelines:}

As objectives for the second stage of the development plan, the City Council proposes the following action:

- To integrate the power station area into the municipality of Sant Adriá. This will permit better access to the sea, provide the area with a beach and also help to consolidate it within the urban structure of "Barcelonés Nord" (Northern Barcelona).

- To connect the area's communications infrastructure and civil axes with those of the rest of the coastal strip.

- To incorporate strategies for urban sustainability in order to reduce the environmental impact of the new urban development. This will help to minimise the consumption of energy, water and other resources and to reduce the emission of greenhouse gases to the minimum.

- To recover the waterfront and provide Sant Adriá del Besos with direct access to the sea and create a new beach area.
- To provide a mix of different uses: residential, commercial, hotel and tourism services, offices, educational and general activities. All of these will be related to the coastal area and should help to create employment.

- To reuse the old power station building for cultural and/or museum uses.

B. Urban Planning Standards.

As detailed in Table 1

Total surface area of the new development: $280,526 \mathrm{~m} 2$

Density index: $1.60 \mathrm{~m} 2 \mathrm{cap} / \mathrm{m} 2$ floor

Maximum surface: 448,841.60 m2floor

TABLE I. DETAILED TABLE OF URBAN PLANNING STANDARDS

\begin{tabular}{|l|l|r|}
\hline \multicolumn{2}{|c|}{$\%$ Occupancy according uses } & \multicolumn{1}{c|}{ Surface area } \\
\hline $\begin{array}{l}85 \% \\
\text { Residential }\end{array}$ & $76,5 \%$ Residential & $343.363,82 \mathrm{~m} 2$ \\
\cline { 2 - 3 } & $8,5 \%$ Hotels & $38.151,54 \mathrm{~m} 2$ \\
\hline $\begin{array}{l}15 \% \\
\text { Non Residential }\end{array}$ & $60 \%$ Commercial & $40.395,74 \mathrm{~m} 2$ \\
\cline { 2 - 3 } & $40 \%$ Offices & $26.930,50 \mathrm{~m} 2$ \\
\hline $100 \%$ TOTAL & \multicolumn{2}{|c}{$448.841,60 \mathrm{~m} 2$} \\
\hline
\end{tabular}

C. Environmental guidelines

1) Energy

Residual energy

- The use of residual energy from major water treatment plants (Metrofang) and from the electricity generated by cogeneration (Districlima)

Metrofang will allow the $100 \%$ recovery of residual heat and PVE incineration will permit the recovery of $30 \%$ of the electricity produced through cogeneration.

2) Protection of biodiversity

3) Water cycle

4) Waste treatment

5) Biodiversity

6) Protection against the sea level rise Should

protect of the sea level rise

\section{URBAN PROPOSAL}

The urban proposal "Fig. 11" is based on previously formulated planning guidelines: 


\section{A. Access to the sea.}

Future development will provide access to the sea for the municipality of Sant Adriá and connections with the neighbouring municipalities of Badalona and Barcelona that will overcome the current island effect.

The existing urban structure is supported by a road system that provides connection with various roads located on the other side of the railway line and with the road network of the neighbouring municipality of Badalona. Underground passing points are proposed to provide access for vehicles and pedestrians.

This will make it possible to overcome the historical barrier that the railway has presented since its construction in 1860 . It will also provide access to the sea for the population of Sant Adriá. (This is therefore a plan that unites rather than separates).

\section{B. Sustainable mobility:}

The new development proposes the prolongation of the present tram line. This would cross the River Besos, running parallel to the current railway line, and would then continue on as far as Badalona, with various stops in Sant Adriá.

The pedestrian axis and bicycle lane would also be extended from the Forum of Cultures area. A footbridge would connect this area to the seaside promenade and the beaches of Sant Adria and thereby to the rest of Barcelona's seafront.

\section{Mixture of uses}

The proposed zoning would combine residential uses with hotels and other tourism-related functions, offices and shops.

D. Design strategies .

- Plans include the construction of a maritime promenade between the new building and the beaches which will be provided with amenities such as bars, restaurants and small businesses associated with tourist activity.

- It will be necessary to take into account the threat of an increase in sea level as a result of climate change. The whole of the new sector will therefore need to be located at a height of at least $3 \mathrm{~m}$ above the current level of the beach in order to protect it from the battering of the storm surges. These often come from the east and are caused by a phenomenon known as the "Llevantada", which occurs from time to time. Increasing the ground level will also make it possible to build above the great collector that currently runs along the edge of the beach. The beaches will also be regenerated in order to increase their size.

- The position and of the new building, which will progressively increase in height, will allow all of its apartments to enjoy views of the sea, without any of them being left in the shade. Its orientation will also allow the whole building to receive the benefits of the sea breeze.

- The positions and shapes of the highest buildings at the end of the alignments will create a unique urban landscape.

- The area where the new building is concentrated will be structured with urban elements belonging to the Mediterranean urban tradition. The main street in the built up area will therefore take the form of a "rambla" or promenade. This will lead to a square, located in front of the new power station museum, which will look out towards the sea.

- The square will be is located above an underground car park which will provide parking for vehicles coming from the rest of the metropolitan area.

- The main route for road traffic will cross at this level to connect with the Badalona walkway. The square will extend towards the sea on a pier raised upon stilts. This pier will be reminiscent of that of the former docks that were used for supplying fuel from boats. It will also incorporate recreational activities for tourists.

- The power station building will be recovered for museum and cultural uses.

- An educational amenity will be located on the neighbouring plot, next to the power station building. This will be destined for the construction of a vocational training centre.

\section{ENVIRONMENTAL OBJECTIVES}

\section{A. Protection of biodiversity}

In order to protect and increase the biodiversity of the mouth of the River Besos, it is proposed to create an urban park next to the mouth of the River Besos which will then act as a zone of transition between the natural space of the river and the urban development in the new sector. The vegetation of the park will be introduced into the heart of the housing estate creating alternative routes to the roads.

An increase in marine biodiversity will also be promoted through the construction of artificial reefs along the coastal fringe located opposite the beach.

\section{B. Energy}

All of the new buildings constructed will have to comply with the NZEBs standard in order to minimise carbon emissions. To achieve this, they will be projected according to strategies that minimise energy consumption. The resulting energy demand will be fully covered with by residual energy produced by the treatment plants in the area plus by the active exploitation of renewable energy. Three types of strategies will be pursued to achieve this: 
1) Passive systems

- Passive solar design

- Insulation,

- Regulation of solar radiation

- Cooling by ventilation

2) Active systems

Energy efficient installations:

- Low energy building: The maximum level of efficient energy certification: level A of the CTE (Spain's official energy regulation certification)

- Air renewal via a heat exchanger

- Geothermal energy

Heat and cold supplied by the district heating, (districlima) of Poble Nou.

Active use of renewable energy:

- Solar thermal energy

- Solar photovoltaic energy

- Mini windmill energy plant.

\section{Water cycle}

As the water from the groundwater reserves could be polluted, it cannot be used for domestic consumption. The strategies used will therefore focus on encouraging water saving and on the appropriate management of rain water: Minimizing the consumption of water by buildings.

- Taking advantage of rain water and storing it in the park's lagoons.

- $\quad$ Reusing grey waters to irrigate the gardens and green areas.

\section{Waste treatment}

This will include:

The selective collection of $80 \%$ of the waste created

Reducing the misuse of the remaining water as much as possible

Reusing rubble from the demolition of previous buildings for the new ones

The management of unpolluted, fertile land obtained by earth movements in order to create spaces destined for public parks.

The management of land derived from earth movements in order to increase the height of the new urbanised area.

\section{E. Biodiversity}

The action undertaken will include:

The conservation of the biodiversity of the ecological corridor around the River Besos

The conservation and improvement of biodiversity in the delta area, with an increase in the number of tree-lined green areas and a concentration of such spaces in a park next to the mouth of the River Besos.

\section{F. Protection against the sea level rise}

To protect of the sea level rise, this new development will be built $3,5 \mathrm{~m}$. above the level of the current beach.

\section{DISCUSSION AND CONCLUSIONS}

In the era of climate change, it is necessary to incorporate strategies that favour urban sustainability if we are to move towards the goal of limiting global warming (which implies preventing an increase in the average temperature of the planet) to a maximum of $2{ }^{\circ} \mathrm{C}$ by the year 2050 .

This important challenge for governments and civil society can only be tackled by reducing carbon emissions and the environmental impact of urban development.

Once the main problems associated with urban growth and the planning of new urban developments have been identified as shown in this article with reference to the example of the Besos power station area - it is necessary to base the new development on a catalogue of simple and understandable strategies that increase its global sustainability. We have done this in the belief that we can achieve overall results that will improve local processes and allow us to obtain similar results, but with lower levels of energy consumption and improved land use. In this way, it will be possible to reduce the production of waste and pollution and to achieve the final goal of creating a lively and liveable city.

In our example of the plan for the Besos power station area, we also found that applying sustainable strategies was not an obstacle to design, but instead offered an opportunity for creativity.

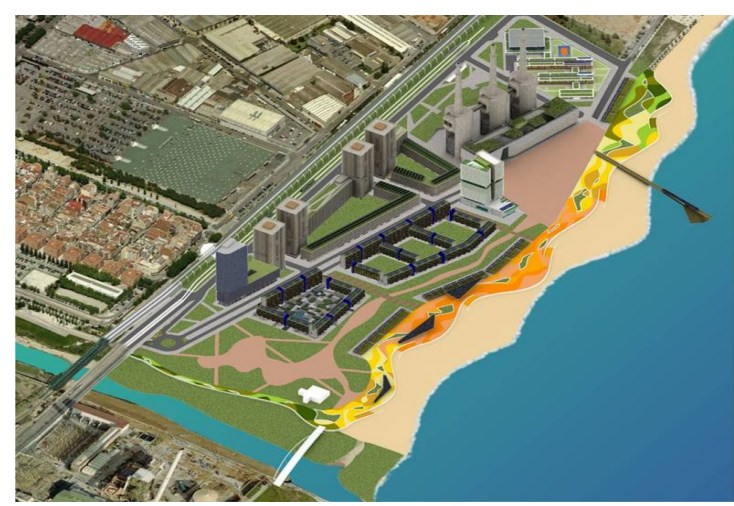

Figure 11. Rendering of the proposal 


\section{REFERENCES}

Bibliographical archive:

[1] J. Sobreques, "Historia de Barcelona, La Ciutat Industrial (1833-1897)", vol. 6. Ed. La Magrana, 1983, pp. 220.

[2] J. Busquets, "La remodelación dels teixits urbans, en Barcelona 1997-2004, del desenvolupament a la ciutat de qualitat", Ed. Ajuntament de Barcelona, 2004, pp. 156

[3] P. Figueras, "La gestió als barris en Barcelona la segona renovación", Ed. Ajuntament de Barcelona, 1996, pp. 121.

[4] Q. Garriga, "The General Metropolitan Plan in Contemporary Barcelona 1856-1999”, Ed. Institut d'edicions, 1999, pp. 176.

[5] V. Bettini, "Elementos de ecología urbana”, Ed. Trotta, Madrid 1998.

Hemerographic archives

E. Sevillano, Diario EL PAIS, 3nov.2014, pag.30.

Electronic resources

IPCCs Fifth Assessment Synthesis Report. 